\title{
Successful treatment of hemoptysis caused by a type 2 endoleak after thoracic endovascular aortic repair
}

\author{
Eijun Sueyoshi ${ }^{1,2^{*}}$, Hirofumi Koike ${ }^{1,2}$, Ichiro Sakamoto ${ }^{1,2}$ and Masataka Uetani ${ }^{1,2}$
}

\begin{abstract}
Background: Massive hemoptysis is a life-threatening condition and can arise as a complication of conditions. Conversely, hemoptysis rarely occurs as a complication of a ruptured thoracic aortic aneurysm (TAA).

Case presentation: A 76-year-old male had a history of surgical replacement of the whole aortic arch due to a TAA. Three years after the surgery, severe hemoptysis occurred, which resulted in the patient's emergency hospitalization at our hospital. The patient was diagnosed with ruptured pseudoaneurysms of the aortic arch. Emergency thoracic endovascular aortic repair (TEVAR) was performed. After that, the hemoptysis stopped, and the patient was discharged. Two months later, the hemoptysis reccurred so the patient was re-admitted to our hospital. CT showed a type 2 endoleak from the bronchial artery. The anastomotic pseudoaneurysms remained. As re-rupturing of the anastomotic aneurysms due to a type 2 endoleak was suspected, transcatheter arterial embolization was performed to treat the type 2 endoleak. The patient's hemoptysis stopped, and he was discharged.

One year later, CT showed that the anastomotic pseudoaneurysms had disappeared, and the diameter of the aorta had also reduced.
\end{abstract}

Conclusion: We present a case of hemoptysis caused by a type 2 endoleak that occurred after TEVAR for a ruptured TAA. The hemoptysis was secondary to aortobronchial fistulas caused by anastomotic aortic pseudoaneurysms. Transcatheter arterial embolization of the type 2 endoleak was very effective against the hemoptysis, and the pseudoaneurysms also disappeared. No such cases have been reported previously.

Keywords: Aortic aneurysm, Rupture, Hemoptysis, Embolization, Endoleak

\section{Background}

Massive hemoptysis is a life-threatening condition and can arise as a complication of conditions such as tuberculosis, bronchiectasis, bronchial carcinoma, and pulmonary aspergilloma (Julià-Serdà et al. 1996). Conversely, hemoptysis rarely occurs as a complication of a ruptured thoracic aortic aneurysm (TAA). However, in a large percentage of cases of ruptured TAA-induced hemoptysis the hemoptysis is massive, and hence, such cases are associated with a high mortality rate when they are not diagnosed and treated early (Julià-Serdà et al. 1996). Recently,

\footnotetext{
* Correspondence: sueyo@nagasaki-u.ac.jp

'Department of Radiology, Nagasaki University School of Medicine, Nagasaki, Japan

${ }^{2}$ Department of Radiological Science, Nagasaki University Graduate School of Biomedical Sciences, Nagasaki, Japan
}

thoracic endovascular aortic repair (TEVAR) has become a common treatment for ruptured TAA.

We present a case of hemoptysis secondary to aortobronchial $(\mathrm{AB})$ fistula formation caused by a type 2 endoleak, which arose after TEVAR for a ruptured TAA.

\section{Case presentation}

A 76-year-old male had a history of surgical replacement of the whole aortic arch due to a TAA (total arch replacement with elephant trunk). Three years after the surgery, severe hemoptysis occurred, which resulted in the patient's emergency hospitalization at our hospital. On arrival, massive hemoptysis $(400 \mathrm{~mL})$ and hypotension were seen. The patient's initial blood pressure was 79/42 $\mathrm{mmHg}$. His hypotension resolved after the intravenous administration of crystalloid fluids. Laboratory tests showed a 
hemoglobin level of $7.3 \mathrm{~g} / \mathrm{dL}$. The patient received blood transfusions, and a computed tomography (CT) scan was performed.

The CT images showed two aortic pseudoaneurysms, related to the aortic anastomoses. They were attached to the trachea and the left bronchus, which was suggestive of $A B$ fistula formation (Fig. 1). The patient was diagnosed with ruptured pseudoaneurysms of the aortic arch. Emergency TEVAR was performed under general anethesia. Two conformable TAG thoracic devices (W.L Gore and Associates, Flagstaff, AZ, USA; diameter: $34 \mathrm{~mm} x$ length: $200 \mathrm{~mm}$, diameter: $37 \mathrm{~mm} \times$ length: $200 \mathrm{~mm}$ ) were inserted into the region extending from the aortic arch (elephant trunk) to the descending aorta.

After that, the hemoptysis stopped, and the patient was discharged. Two months later, the hemoptysis reccurred so te patient was re-admitted to our hospital. CT showed a type 2 endoleak from the bronchial artery. The pseudoaneurysms remained (Figs. 2a and b). At that time, blood test results were as follows: hemoglobin level of $9.3 \mathrm{~g} / \mathrm{dL}$; peripheral white blood cells $5.4 \times 10^{9} / \mathrm{L}$; C-reactive protein $0.4 \mathrm{mg} / \mathrm{L}$; and erythrocyte sedimentation rate $12 \mathrm{~mm} / \mathrm{h}$.

As re-rupturing of the pseudoaneurysms due to a type 2 endoleak was suspected, transcatheter arterial embolization (TAE) was performed to treat the type 2 endoleak.

First, the femoral artery was punctured, and aortography was conducted. Aortography did not show any type 1 or 3 endoleaks. However, a type 2 endoleak from the brachiocephalic artery was confirmed.

Next, the right brachial artery was punctured, and brachiocephalic arteriography was carried out, which showed a type 2 endoleak into the aortic pseudoaneurysms from the supreme intercostal artery via the bronchial artery (Fig. 2c). We used the triple coaxial technique to treat it. A 4F diagnostic catheter was advanced through a 2.7-F non-tapered microcatheter (Sniper 2 Selective Revolution; Terumo-Clinical Supply). Next, a 1.9-F non-tapered microcatheter (Marvel; Tokai, Kasugai, Japan) was advanced through a 2.7-F microcatheter, which was coaxially introduced through a catheter. The 1.9-F non-tapered microcatheter was advanced into the aortic sac via the bronchial artery. TAE was performed by injecting $5 \mathrm{ml}$ of an $n$-butyl cyanoacrylate (NBCA) (B. Braun, Melsungen, Germany): Lipiodol Ultra-Fluide (Guerbet, Roissy, France) (ratio: 1: 3) mixture into the aortic sac and pseudoaneurysms via the inflowing artery. After the TAE, the type 2 endoleak disappeared (Fig. 2d). The patient's hemoptysis stopped,

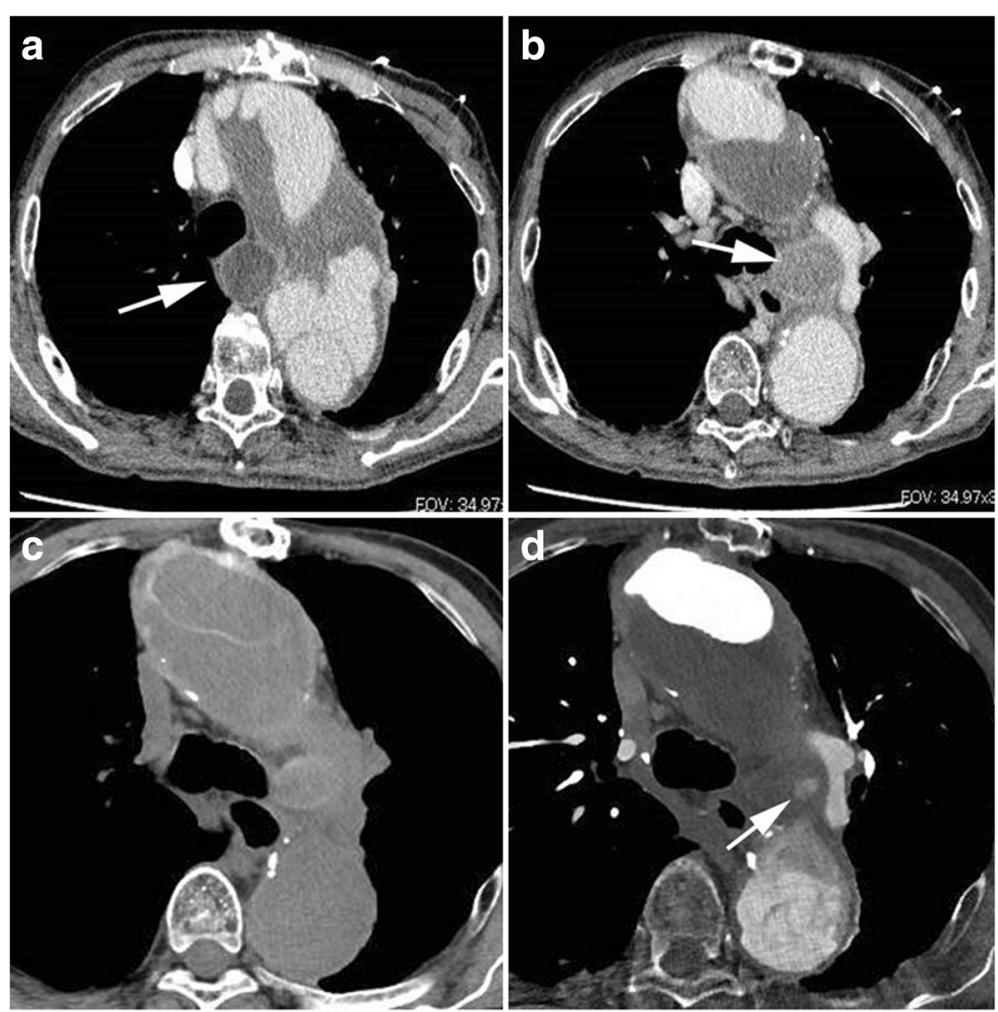

Fig. 1 A 76-year-old male with massive hemoptysis. $\mathbf{a}$ and $\mathbf{b}$. CT showed two aortic pseudoaneurysms (arrows), which were in contact with the aortic anastomoses. They were attached to the trachea and left bronchus, respectively, which was suggestive of AB fistula formation. $\mathbf{c}$ and $\mathbf{d}$. Two months before $\mathbf{a}$ and $\mathbf{b}$, CT showed that an aortic pseudoaneurysm had blood flow (arrow). After that, the psuedoaneurysn increased in size 

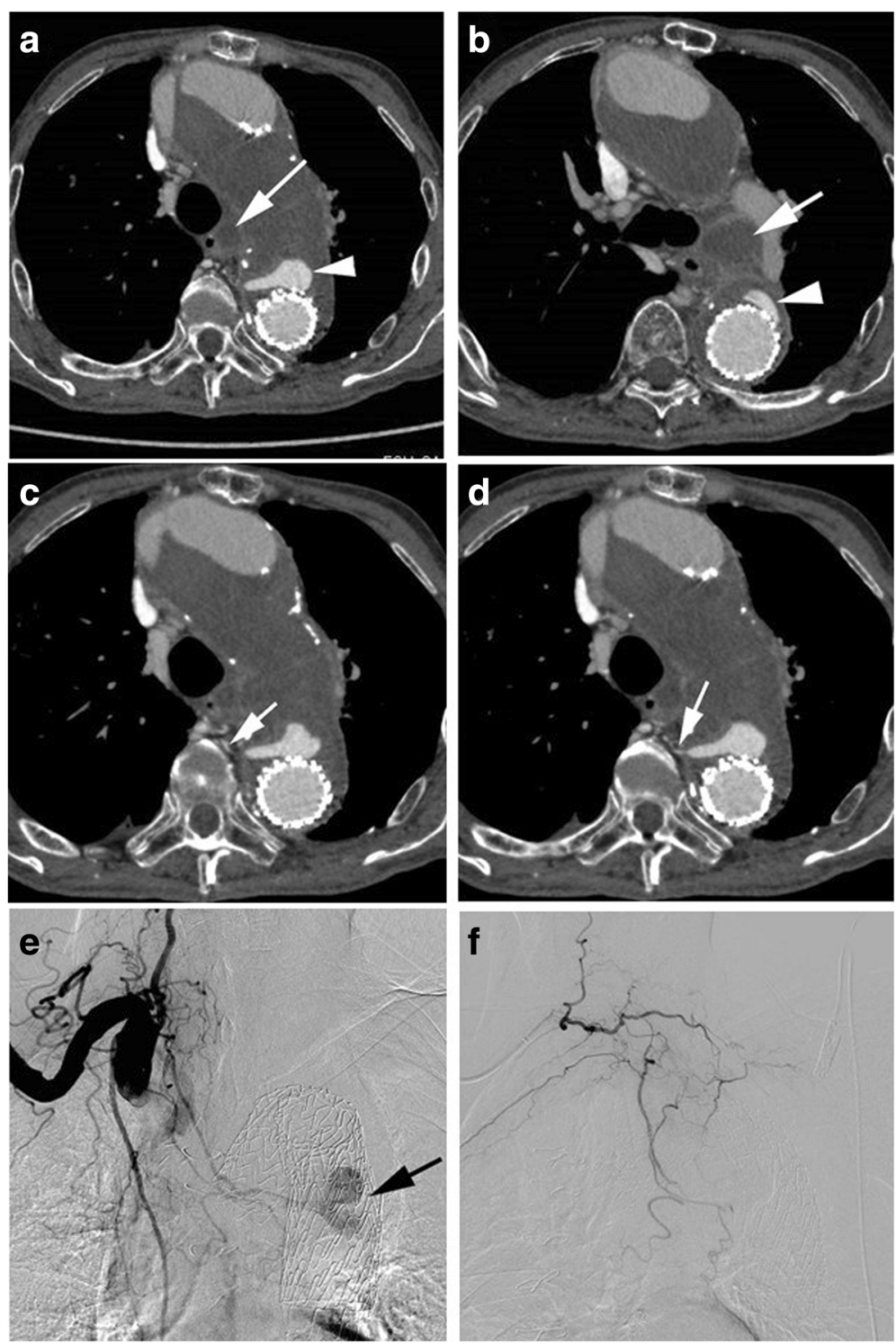

Fig. 2 a and $\mathbf{b}$. Two stent-grafts were inserted into the region extending from the aortic arch (elephant trunk) to the descending aorta. CT showed a type 2 endoleak. The pseudoaneurysms remained (arrows). $\mathbf{c}$ and $\mathbf{d}$. CT showed a type 2 endoleak via the bronchial artery (arrows). e. Brachiocephalic arteriography showed a type 2 endoleak (arrow) into the aortic pseudoaneurysms from the supreme intercostal artery via the bronchial artery. f. After TAE, the type 2 endoleak disappeared

and he was discharged. There was no further recurrence of the hemoptysis. One year later, CT showed that the pseudoaneurysms had disappeared, and the diameter of the aorta had also reduced (Fig. 3). Gallium scintigraphy showed no abnormal accumulation. The patient's progress has been good.

Hemoptysis is a rare complication of TAA. It usually occurs after the formation of an $A B$ fistula. In such cases, the hemoptysis can be massive if it is not treated surgically (Ahmadi et al. 2014). A high degree of suspicion regarding this entity is the key to its appropriate management. It is estimated that $5 \%$ of patients who present with hemoptysis suffer massive hemoptysis, a life-threatening condition that can cause airway obstruction and exsanguination. It exhibits a mortality rate of 30-70\% (Phang et al. 2001). Nowadays, such hemoptysis can be treated using endovascular techniques involving stent-grafts (Kokotsakis et al. 2007).

In this case, we first treated the $\mathrm{AB}$ fistula formed by the rupturing of the anastomotic pseudoaneurysms using TEVAR. The hemoptysis initially stopped because the TEVAR blocked the blood flow to the pseudoaneurysms and reduced the pressure within them. However, 2 months later the hemoptysis relapsed because a type 2 endoleak 


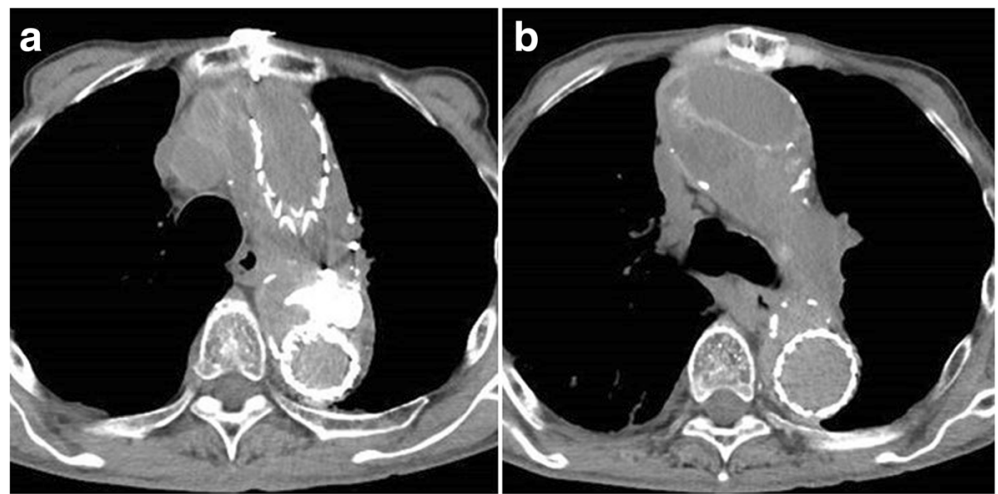

Fig. $3 \mathbf{a}$ and $\mathbf{b}$. One year later, CT showed that the anastomotic pseudoaneurysms had disappeared, and the diameter of the aorta had also reduced

increased the pressure within the aortic sac and pseudoaneurysms. Moreover, the type 2 endoleak supplied blood flow into the aortic sac and pseudoaneurysms.

Previously, Synowiec T, et al. reported that hemoptysis was a unique symptom of type $1 \mathrm{~A}$ endoleaks that occur after TEVAR and led to the rupturing of thoracic aneurysms (Synowiec et al. 2013). However, to the best of our knowledge, this is the first report about hemoptysis caused by a type 2 endoleak after TEVAR.

The incidence of endoleak after TEVAR ranges from $5 \%$ to $20 \%$, which is similar to that after endovascular abdominal aortic aneurysm repair (EVAR) (Parmer et al. 2006). Type 2 endoleaks are most commonly seen after EVAR. Type 1 and 2 endoleaks occur at similar rates after TEVAR (Stavropoulos et al. 2009). An accepted management method is aggressive endovascular repair of type 1 and 3 endoleaks along with observation for type 2endoleaks (Alsac et al. 2011). Collateral circulation in the chest involving the thoracic aorta is not so well developed compared to collateral vessels in the abdomen, making transarterial embolization of thoracic endoleaks difficult (Stavropoulos et al. 2009). To our knowledge, there is no consensus treatment option for type 2 endoleaks.

In the present case, rupturing and hemoptysis occurred due to a type 2 endoleak, which was considered to be an absolute indication for embolization.

It is still unclear if embolization of the endoleak nidus alone achieves the same outcomes as embolization of the endoleak nidus and the associated branch vessels. In the current case, using the triple coaxial technique, a microcatheter was inserted into the aortic sac via the bronchial artery. TAE was performed by injecting $5 \mathrm{ml}$ of an A: Lipiodol Ultra-Fluide (ratio: 1: 3) mixture into the aortic sac/pseudoaneurysms via the inflowing artery. After the TAE, the type 2 endoleak disappeared. In this case, TAE was very effective against the patient's hemoptysis, and the pseudoaneurysms disappeared.
However, further investigation is necessary to identify more effective and appropriate embolization methods.

\section{Conclusions}

We described a case of hemoptysis secondary to AB fistula formation, which was caused by a type 2 endoleak that developed after TEVAR for a ruptured TAA. No such cases have been reported previously. TAE of the type 2 endoleak was very effective against the hemoptysis, and the pseudoaneurysms also disappeared.

\section{Abbreviations}

AB fistula: Aortobronchial fistula; CT: Computed tomography; NBCA: N-butyl cyanoacrylate; TAA: Thoracic aortic aneurysm; TAE: Transcatheter arterial embolization; TEVAR: Thoracic endovascular aortic repair

\section{Funding}

This study was supported by JSPS KAKENHI Grant Number 15 K09894.

Availability of data and materials

Please contact author for data requests.

\section{Authors' contributions}

ES, HK, and IS participated in the design of the study. ES, HK, and MU conceived of the study, and participated in its design and coordination and helped to draft the manuscript. All authors read and approved the final manuscript."

Ethics approval and consent to participate

Our institutional ethics committee approved this case report and the committee's reference number is 17121829 .

\section{Consent for publication}

Informed consent was obtained from all individual participants included in the study.

Competing interests

The authors declare that they have no competing interests.

\section{Publisher's Note}

Springer Nature remains neutral with regard to jurisdictional claims in published maps and institutional affiliations. 
Received: 7 February 2018 Accepted: 30 May 2018

Published online: 22 October 2018

\section{References}

Ahmadi ZH, Ansari Aval Z, Saghebi SR, Kianfar AA, Hashemian SM, Kahkouee S, Roozdar S, Naderi H (2014) Massive hemoptysis, a presentation of invasion of aneurysm of descending aorta to bronchopulmonary tree. Arch Iran Med 17(11):786-788

Alsac JM, Khantalin I, Julia P, Achouh P, Farahmand P, Capdevila C, Isselmou KO, Fabiani JN (2011) The significance of endoleaks in thoracic endovascular aneurysm repair. Ann Vasc Surg 25:345-351

Julià-Serdà G, Freixinet J, Abad C, Rodriguez de Castro F, López L, Caminero J, Cabrera P (1996) Massive hemoptysis as a manifestation of fistulized thoracic aortic aneurysms into the bronchial tree. J Cardiovasc Surg 37(4):417-419

Kokotsakis J, Misthos P, Athanasiou T, Romana C, Skouteli E, Lioulias A, Kaskarelis (2007) Endovascular stenting for primary aortobronchial fistula in association with massive hemoptysis. Tex Heart Inst J 34:369-372

Parmer SS, Carpenter JP, Stavropoulos SW, Fairman RM, Pochettino A, Woo EY, Moser GW, Bavaria JE (2006) Endoleaks after endovascular repair of thoracic aortic aneurysms. J Vasc Surg 44:447-452

Phang LY, Wong D, Agasthian T (2001) Management of life threatening hemoptysis. Asian Cardiovasc Thorac Ann 9:200-203

Stavropoulos SW, Tucker J, Carpenter JP (2009) Thoracic endoleak embolization using a direct percutaneous puncture of the endoleak through lung parenchyma. J Vasc Interv Radiol 20:1248-1251

Synowiec T, Warot M, Burchard P, Paschke L, Lysiak Z, Checiński P (2013) Hemoptysis as a first symptom of endoleak after thoracic endovascular aortic repair, which caused aortic rupture and required complex management. Videosurgery Miniinv 8(2):178-181

\section{Submit your manuscript to a SpringerOpen ${ }^{\circ}$ journal and benefit from:}

- Convenient online submission

- Rigorous peer review

- Open access: articles freely available online

- High visibility within the field

- Retaining the copyright to your article

Submit your next manuscript at $\boldsymbol{s p r i n g e r o p e n . c o m ~}$ 